\title{
Post-fledging survival and dispersal of shy albatross from three breeding colonies in Tasmania
}

\author{
R. Alderman ${ }^{1,2, *}$, R. Gales ${ }^{1}$, A. J. Hobday ${ }^{2,3}$, S. G. Candy ${ }^{4}$ \\ ${ }^{1}$ Department of Primary Industries, Parks, Water and Environment (DPIPWE), Hobart, Tasmania 7001, Australia \\ ${ }^{2}$ Quantitative Marine Science Program and School of Zoology, University of Tasmania, Hobart, Tasmania 7001, Australia \\ ${ }^{3}$ Wealth from Oceans Flagship, CSIRO Marine and Atmospheric Research, Hobart, Tasmania 7001, Australia \\ ${ }^{4}$ Australian Antarctic Division, Kingston, Tasmania 7050, Australia
}

\begin{abstract}
Limited knowledge of the movements of post-fledging albatross represents a significant gap in understanding albatross biology and conservation. Without clearer understanding of at-sea distribution and mortality during this life-history stage, the threats to albatrosses cannot be managed appropriately. We investigated this early at-sea behaviour of shy albatrosses Thalassarche cauta which breed only in Tasmania. We deployed 48 satellite transmitters on fledgling birds from each of the 3 Tasmanian populations over 4 separate seasons. We observed population differences in the atsea distribution, with the northern Albatross Island population foraging exclusively in southern Australian shelf waters to the west of the breeding colony. Birds from the 2 populations in southern Tasmania (Mewstone and Pedra Branca) also favoured these areas; however, they showed greater tendency to traverse the high seas and forage further west. These differences in spatial distribution mean populations have different exposure to fisheries and consequent risk of bycatch. Analysis of the satellite data and supporting evidence from band recoveries showed that juvenile mortality is highest in the period immediately after fledging. We speculate that this is related to foraging failure of naive birds. Differences between the 3 populations in post-fledging mortality were apparent. Albatross Island birds have greater chance of surviving the crucial initial learning period after fledging than either of the 2 southern populations, possibly due to proximity to food resources.
\end{abstract}

KEY WORDS: Satellite tracking $\cdot$ Foraging grounds $\cdot$ Juvenile albatross $\cdot$ Survival $\cdot$ Thalassarche cauta

\section{INTRODUCTION}

Albatrosses are wide-ranging species found in most oceans of the world, returning to breed at a few discrete colonies, typically on remote offshore islands. Albatrosses are among the most threatened bird taxa, with 18 of 22 species of albatross classified as threatened under aggregated IUCN criteria (IUCN 2008). Despite general protection measures for breeding habitats and individuals, many populations are still in decline. Commercial fishing is recognised as a key threatening process, and dramatic declines of albatross populations around the globe have been compellingly linked with accidental mortality associated with fishing operations, primarily those in longline (Tasker et al. 2000, Tuck et al. 2001, Nel et al. 2002) and trawl (Bartle 1991, Watkins et al. 2008) fisheries. Thus, identifying the spatial and temporal overlap with fisheries is fundamental to understanding risk and implementing effective conservation measures for these iconic species. Determining this overlap is not easy, however, as the majority of an albatross' life is spent ranging widely over the oceans and its foraging behaviour and movements are difficult to study. Adding further complication is the variation in distribution and behaviour, and hence risk, between populations, gender, age classes and breeding status (Prince et al. 1992, Weimerskirch et al. 1997, Hedd et al. 2001, Huin 2002). A first step in determining potential causes of at-sea mortality is to determine the at-sea distribution patterns and the baseline mortality of various life stages. 
Tracking studies have proven particularly important for identifying the spatial and temporal distribution of albatross populations and interaction risk with fisheries (reviewed in Burger \& Shaffer 2008). Adults have been the focus of most research, particularly during periods of incubation and provisioning at breeding colonies (Jouventin \& Weimerskirch 1990, Prince et al. 1992, Fernández et al. 2001, Nel et al. 2002, Terauds et al. 2006a), because expensive telemetry gear can be reliably retrieved from birds returning to a colony. Tracking data to determine the distribution of nonbreeding birds, particularly juveniles, are generally lacking in albatrosses (Birdlife International 2004). The movements of young albatross between fledging and first re-sight at the natal colony (between 3 and $7 \mathrm{yr}$ depending upon the species) have not been widely studied. Juvenile albatross behaviour is not conducive to studies relying on archival data-loggers because of the prolonged and unpredictable absence from colonies and relatively high juvenile mortality rates (Weimerskirch et al. 2006). Consequently, distribution has typically been obtained from at-sea observations and band returns (Brothers et al. 1997, Waugh et al. 1999) or inferred from analysis of bycatch (e.g. Abbott et al. 2006). Juvenile birds may experience different levels of fisheries mortality compared to adults because of differences in foraging behaviour (e.g. Weimerskirch et al. 1993, 2006). Additionally, during the many post-fledging years spent at sea, distributions are less constrained and are potentially much larger than those of adults. The foraging behaviour and life-history characteristics of juvenile albatrosses during these years at sea are unknown; however, observed declines in many albatross populations have been linked to juvenile survival (e.g. Arnold et al. 2006, Terauds et al. 2006b).

Survivorship analyses of albatrosses typically define a single juvenile class as the age to the first re-sight at the natal colony or first recorded breeding attempt (e.g. Inchausti \& Weimerskirch 2001, Cuthbert et al. 2003, Terauds et al. 2006b), and mortality rates are assumed to be uniform across the juvenile cohort. However, demographic parameters (breeding success and survival) in adult seabirds have been shown to improve with age or experience (Weimerskirch 1992, Pinaud \& Weimerskirch 2002, Barbraud \& Weimerskirch 2005, Nevoux et al. 2007). Even within the juvenile cohort, it is reasonable to assume that mortality rates vary with age and experience. In fact the greatest mortality rate may occur immediately after birds leave the colony and are inexperienced in flying and foraging. Understanding the early life distribution and survival is important in designing conservation measures to enhance albatross population persistence. The present study used satellite telemetry to address the postfledging stage for one southern hemisphere species, the shy albatross Thalassarche cauta.

The shy albatross breeds exclusively on 3 offshore islands around Tasmania, Australia (Fig. 1). Typically annual breeders, the total breeding population is currently estimated to be approximately 15000 pairs (Department of Primary Industries, Parks, Water and Environment [DPIPWE] unpubl.), although the overall trend of the population is unknown. The largest population nests at Mewstone ( $67 \%$ of total pairs), which is remote and topographically difficult to monitor, and population trends are unknown. The nearby breeding colony on Pedra Branca $(<2 \%$ of pairs) is extremely small and has undergone a dramatic decrease in recent years (DPIPWE unpubl.). The Bass Strait Albatross Island population ( $29 \%$ of pairs) is the most studied, in part as the island is most easily accessed. After historical decimation in the late 1800s (Plomley 1966), this population has recovered from a low of approximately 200 breeding pairs per year in 1909 (Armstrong 1910) to 5000-5500 pairs in 2001, and has remained stable since (DPIPWE unpubl.).

The majority of knowledge regarding shy albatross foraging behaviour has been derived from Albatross

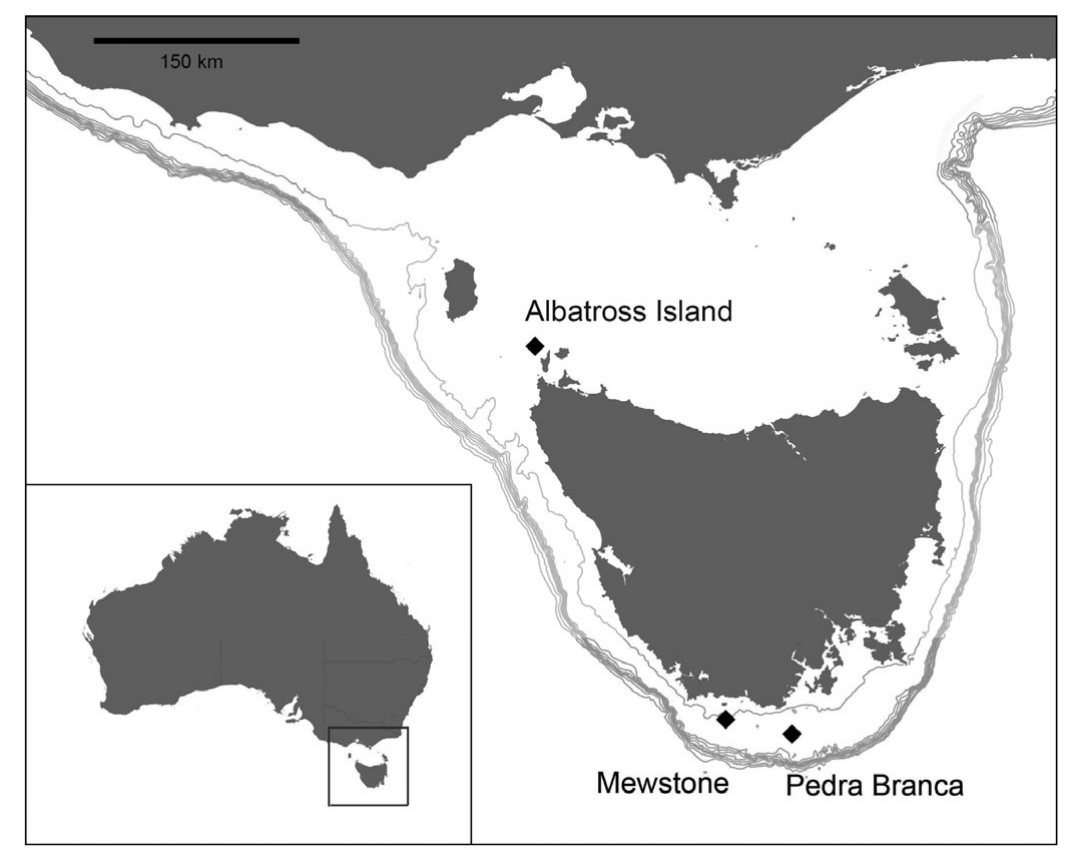

Fig. 1. Thalassarche cauta. Location of shy albatross breeding islands around Tasmania 
Island adults, predominantly focusing on breeding birds. Tracking studies of adult birds from all 3 populations have shown that shy albatross have a limited foraging range in southeast Australian waters, within $200 \mathrm{~km}$ of the colony during the breeding period (Hedd et al. 2001). Dispersal of post-breeding birds from the 3 colonies is less well known; however, all tracking studies to date have indicated that adult birds are resident in waters close to breeding colonies year-round (DPIPWE unpubl.). Furthermore, attendance studies on Albatross Island (Hedd \& Gales 2005), band resights and observations at all 3 colonies show that a large proportion of adults visit the island during the non-breeding period. Knowledge of the foraging behaviour and distribution of juvenile shy albatrosses is extremely limited, relying upon band returns, at-sea observations (Brothers et al. 1997) and some bycatch analysis (Abbott et al. 2006). In the present study we report for the first time on survival and distribution of post-fledging shy albatross from the 3 populations over 4 seasons based on satellite tracking data.

\section{MATERIALS AND METHODS}

Transmitter deployment. A total of 48 satellite transmitters were deployed on pre-fledging shy albatross chicks from the 3 breeding islands in March and April of 4 years: 1996, 2004, 2005 and 2006. Units were from 3 different manufacturers and encompassed a variety of duty cycle configurations (transmission periods and intervals; Table 1). The anticipated transmission time ranged from 3 to 8 mo until the power supply was exhausted.

Transmitters were attached to feathers on the dorsal midline of each bird using cloth tape and quick-setting glue. With this attachment method, units were expected to remain attached until the feathers moulted or the glue/tape adhesive lost integrity (e.g. Lawton et al. 2008). Birds were also fitted with individually numbered metal or coloured plastic (darvic) bands. Blood samples were collected from the tarsal vein of birds in 2004 and 2005 for the molecular determination of gender based on methods of Griffiths \& Tiwari (1995). Bird mass at the time of tagging was obtained in 2004, 2005 and 2006 by weighing the researcher whilst holding the bird on a platform scale (accurate to $50 \mathrm{~g}$ ), then subtracting the mass of the researcher.

Satellite data indicated some birds did not leave the island (see 'Materials and methods - Assigning mortality to tracked individuals'). We revisited all nests involved in the 2004 and 2005 deployments in the months post-fledging to search for evidence of a recently deceased chick or remains of the transmitter and/or attachments. One bird from Albatross Island was recovered dead several metres from the nest with the satellite transmitter firmly attached, but no other chicks were located. Based on nest searches, we are confident that all other chicks left their nest areas with transmitters attached. Accurate Argos locations from 2 individuals on Mewstone indicated that they were transmitting from the base of inaccessible cliffs, and fatal crashes during the fledging period are frequently observed (R. Alderman pers. obs.).

The date of fledging was identified by visualising individual tracks in GIS software (Manifold $7 \times$ Pro, 2006) and identifying the last location that was unambiguously on land, considering both the accuracy class of the location and the position of subsequent locations. This date was only accurate to within a $24 \mathrm{~h}$ period as the units were programmed with various duty cycles and fledging may have occurred at any time during the period the unit was not transmitting (up to $24 \mathrm{~h}$ in some cases; Table 1).

Assigning mortality to tracked individuals. The mortality of post-fledging birds was inferred from patterns

Table 1. Thalassarche cauta. Details of the 48 satellite transmitters deployed on post-fledging shy albatrosses. One bird from each colony was tracked in 1996; 6 units each were deployed on Albatross Island and Pedra Branca in 2004, with 8 on Mewstone (including the 2 microwave units); 5 units each were deployed on Albatross Island and Pedra Branca in 2005, with 10 on Mewstone; all 5 transmitters were deployed on Mewstone in 2006. Location error $=$ mean \pm SD

\begin{tabular}{|c|c|c|c|c|c|c|c|}
\hline Year & $\mathrm{N}$ & Manufacturer & $\begin{array}{l}\text { Unit } \\
\text { mass } \\
(\mathrm{g})\end{array}$ & $\begin{array}{l}\text { Duty cycle } \\
\text { (on/off } \\
\text { hours) }\end{array}$ & $\begin{array}{c}\text { Transmission } \\
\text { times } \\
\left(\mathrm{AEST}^{\mathrm{a}}\right)\end{array}$ & $\begin{array}{l}\text { Realised trans- } \\
\text { mission duration } \\
\text { range (d) }\end{array}$ & $\begin{array}{l}\text { Location error } \\
\qquad(\mathrm{km})\end{array}$ \\
\hline 1996 & 3 & Toyocom & 80 & $24 / 24$ & $00: 00-23: 59$ & $84-112$ & $6.2 \pm 14.9$ \\
\hline 2004 & 2 & Microwave & 30 & $6 / 24$ & Not fixed & 8-13 & $3.7 \pm 6.5$ \\
\hline 2004 & 18 & Sirtrack & 32 & $5 / 19$ & $06: 00-10: 59$ & $12-86$ & $4.2 \pm 18.2$ \\
\hline 2005 & 20 & Sirtrack & 50 & $5 / 19$ & $06: 00-10: 59$ & $5-73$ & $3.7 \pm 21.5$ \\
\hline \multirow[t]{3}{*}{2006} & 5 & Sirtrack & 50 & $3 / 3$ & $11: 00-13: 59$ & $2-48$ & $3.7 \pm 8.0$ \\
\hline & & & & $3 / 3$ & $17: 00-19: 59$ & & \\
\hline & & & & $3 / 9$ & $23: 00-01: 59$ & & \\
\hline
\end{tabular}


in the duration of satellite transmission (see Fig. 2). Individuals with sustained transmission from the island or with fewer than $5 \mathrm{~d}$ at sea were assumed to have died soon after leaving the nest and those with greater than $10 \mathrm{~d}$ at sea were considered to have survived this period. Interpreting the fate of individuals based on satellite data alone is problematic and other explanations for premature cessation must first be considered, including attachment failure and transmitter malfunction.

To investigate the possibility that attachment failure caused platform transmitter terminals (PTTs) to cease transmitting prematurely, we compared duration of attachment obtained in the present study with similar comparable studies undertaken on adult shy albatrosses from all 3 colonies, as well as juvenile blackbrowed (Thalassarche melanophrys) and grey-headed (T. chrysostoma) albatrosses and adult Northern and Southern giant petrels (Macronectes halli and $M$. giganteus respectively) on Macquarie Island between 2003 and 2007 ( $\mathrm{n}=39$ ). These studies involved identical attachment methodology, transmitters and tape, and had consistency of personnel. The mean number of days of attachment from these studies was $63 \pm 28 \mathrm{~d}$ (1 SD, range 0 to $121 \mathrm{~d}$ ) (Trebilco et al. 2008, DPIPWE unpubl.) which was significantly higher than the overall average of $40 \pm 28 \mathrm{~d}$ ( $1 \mathrm{SD}$ ) obtained in the present study $\left(t_{82}=-3.868, \mathrm{p}<0.001\right)$. Only 1 deployment in these other studies (a juvenile grey-headed albatross) provided less than $5 \mathrm{~d}$ at sea. This comparison supports our assumption that attachment failure does not account for all the units with little or no at-sea data obtained in the present study.

Transmitter malfunction may also account for premature cessation of transmission (Hays et al. 2007). Four of the Sirtrack transmitters deployed in 2004 experienced intermittent operation while at sea (failing to transmit for between 2 and $14 \mathrm{~d}$ ). This was diagnosed as a problem with one of the on-board software routines (K. Lay, Sirtrack, pers. comm.). Diagnostic data was obtained from all Sirtrack transmitters ( $\mathrm{n}=43$ ). Mean daily battery voltage, current drain, signal strength and platform stability values remained within acceptable functioning ranges for these devices (K. Lay, Sirtrack, pers. comm.) and there were no trends in the timing of transmission or failures to support unit malfunction in those that ceased prematurely. Additionally, there was no consistency of premature transmission failure across 3 manufacturers, 4 different unit configurations and 5 different assembly batches. Thus, we conclude that transmitter malfunction was not a significant factor in the premature cessation of transmissions in the present study.

Finally, we compared the initial flight characteristics (i.e. flight speeds and direction of travel from the colony up to the first $5 \mathrm{~d}$ at sea) of birds that fledged and appear to have died soon after with those that continued to transmit beyond $10 \mathrm{~d}$ at sea. Slower flight speeds and a greater tendency for down-wind travel observed in the former category (see 'Results - Flight characteristics') are further support for the assignment of mortality.

Data processing. The average location error for each transmitter configuration was calculated using position fixes obtained from individuals prior to fledging where location was precisely known (i.e. the nest) to compare the consistency of location accuracy across models. We retained all classes of Argos location and ran an iterative speed filter to discard unrealistic locations that required sustained speeds of $100 \mathrm{~km} \mathrm{~h}^{-1}$ or above (averaged over 3 locations) using the package 'trip' (M. D. Sumner; v. 2006) written in R (R Development Core Team, www.r-project.org./). Flight speeds this high have been shown to be unlikely in other studies of shy albatross foraging (Hedd et al. 2001) and 96\% of the total 4975 locations were retained after this filter. The time that each individual spent within $50 \mathrm{~km}$ grid squares ('time-spent-in-squares') was also calculated using 'trip' (with hourly interpolation intervals), to characterise the at-sea distribution of post-fledging shy albatross. The spatial use of multiple individuals is commonly represented using the time-spent approach (e.g. Bradshaw et al. 2004, Terauds et al. 2006a, Bestley et al. 2008). The time-spent approach additionally controls for the range of duty cycles in the transmitters in this data set.

Argos point locations were also used to investigate flight characteristics, including distances covered, bearing and flight speeds, to assess how these changed over time since fledging and if there were differences in flight characteristics between individuals that survived and those that died soon after fledging. Circular statistics (package 'circular' in R) were used to test for differences in bearing between groups.

Further filtering, based on time and speed between consecutive locations, was applied to the data set for this analysis. Instantaneous flight speeds were derived from the distance and lapsed time between consecutive points. Speeds based on time lapses greater than $12 \mathrm{~h}$ were discarded since the behaviour during this period cannot be reliably estimated. Speeds derived from positions less than $10 \mathrm{~min}$ apart were also excluded from the analysis, as the true distance between locations this close in time is less than the accuracy of the Argos system (Hays et al. 2001) and 10 min was the average duration of satellite passes in this data set (not shown). Individual speed estimates greater than $100 \mathrm{~km} \mathrm{~h}^{-1}$ we also deleted (this is in addition to the iterative speed filter applied for the time-spent analysis; see beginning of this section). Applying these criteria to the 4877 total individual speed estimates 
obtained resulted in $25 \%$ of estimates being discarded (mean $47 \pm 87 \mathrm{~km} \mathrm{~h}^{-1}$ ). Bearing and distances between consecutive locations and between individual locations and natal island were calculated using Matlab programs (v. 7, Mathworks).

Data analysis. To assess how effectively the tracking sample size of individuals might describe the population-level at-sea distribution, we used time-spent-insquares in a saturation curve analysis, an approach adapted from one used on elephant seals Mirounga leonina by Hindell et al. (2003), where complete saturation is achieved when an additional individual contributes no new spatial information to the existing sample. We randomly selected (with replacement) 1 individual from the sample pool and summed the number of squares occupied. A second randomly selected bird was taken from the pool and novel squares (i.e. those not already occupied) tallied and so on until all individuals in the sample pool had been included. This was repeated 1000 times and the average number of new squares contributed by each additional bird was calculated. The cumulative number of average squares occupied was then plotted against the number of individuals tracked at sea. The extent to which the slope of the plotted line approached an asymptote thus provided an estimate of how effectively the sample size in the present study captured the spatial diversity of the species. A relationship between duration of track and number of squares used is expected and this analysis is therefore likely to be sensitive to inclusion of tracks of different lengths. Ideally the analysis is restricted to tracks curtailed to the same length of time, which would only have been possible here if a greater number of tracks were available.

We investigated how juvenile albatross utilised presumed foraging areas at the scale of the individual $50 \mathrm{~km}$ squares. With a continuously searching foraging strategy, theory predicts that when an albatross encounters favourable foraging areas ('good squares'), it will likely remain in or revisit these areas (Veit 1999, Hyrenbach et al. 2002, Pinaud \& Weimerskirch 2007). In contrast, theoretically there is little benefit in remaining in unfavourable foraging areas and so albatross are likely to quickly leave 'poor squares'. Neither the time occupied with foraging nor the success of foraging bouts can be quantified by location data alone; however, we used the patterns in occupancy, i.e. use and re-use, of grid squares to approximate favourable foraging conditions. Each of the $50 \mathrm{~km}$ squares occupied was given a unique identifier. For each albatross, the number of new (novel) squares occupied each day at sea was expressed as a cumulative percentage of the total number of squares occupied for the tracking duration. Consecutive days with few new squares occupied represents a period in which an individual is frequenting previously encountered areas as opposed to foraging into new areas. We compared the occupancy patterns of birds from the 3 colonies to identify potential differences that may be related to observed survival differences.

We then extracted environmental data for each $50 \mathrm{~km}$ grid square each time it was occupied by a bird to investigate how the ocean characteristics changed over time since fledging for birds from each colony. Satellite-based sea surface temperature (SST; Commonwealth Scientific and Industrial Research Organisation [CSIRO] 3 d composite images of night-time passes, $\sim 4.5 \mathrm{~km}$ resolution) and chlorophyll concentration (chl a SeaWiFS 8 d composites, $\sim 9 \mathrm{~km}$ resolution; values $>10$ eliminated) and bathymetry (Australian Geological Survey Organisation [AGSO], $\sim 1.1 \mathrm{~km}$ resolution) were extracted for each square used for the corresponding time period using custom-written Matlab programs. This analysis was structured to test for a difference in environmental conditions experienced over time since fledging by birds from different natal colonies over the first $30 \mathrm{~d}$ at sea, the period for which survival is critical (see 'Results'). This is in contrast to models that test how the environment influences the at-sea distribution (e.g. Bradshaw et al. 2004, Suryan et al. 2006). A period of $30 \mathrm{~d}$ was selected as the limit for these analyses as there was only a single representative for one of the colonies (Pedra Branca) after this time. Linear mixed-effects models (LMM) (Diggle et al. 2001) were fitted separately to $\log$ chl $a, \log$ SST and $\log$ bathymetry with 3 fixed effects: days since fledging (DSF) (as a continuous variable), and Colony, and the Colony by DSF interaction. Random effects incorporated in the LMM were Bird; Bird by DSF; a cubic spline term in DSF, spl(DSF); and the interactions of each of Colony and Bird with spl(DSF) using the ASReml-R package (www.vsni.co.uk/downloads/ asreml; Gilmour et al. 1999). This is the maximal model that incorporates all possible interactions of fixed (Colony) and random (Bird) factors with the linear and nonlinear trend components in DSF. The method of fitting cubic splines within a LMM using ASReml-R is given in Verbyla et al. (1999). As well as random effect variances, the covariance between the Bird and Bird by DSF random effects was estimated. The random effects for fixed effects were tested using sequential Wald tests (Welham \& Thompson 1997) and significance of random effect terms was determined by comparing residual log-likelihoods (Verbyla et al. 1999). In addition, predicted response curves with DSF for each colony were graphed along with the average standard error of the difference as a function of DSF for a set of DSF values in order to investigate the effect of time since fledging on the values of SST, chl a and bathymetry, to examine colony differences in habitat associa- 
tions and to identify interactions between colony and time since fledging. The standard error of the predictions as a function of colony and DSF was obtained from the predict function in the ASReml-R package. Normal quantile plots for both residuals and Bird-level random effects for log chl $a$, log SST and log bathymetry were reasonably well approximated by a normal distribution. There were 10, 9 and 6 birds from Albatross Island, Mewstone and Pedra Branca, respectively, used in the fit of the LMM.

\section{RESULTS}

Of the 48 juvenile birds fitted with satellite transmitters in the present study, 23 (49\%) are assumed to have died upon or soon after fledging. Thirteen (27\%) did not transmit positions beyond the natal colony, of which 8 ceased suddenly during the fledging period and 5 continued to transmit from the island beyond the end of May, when all successful birds had fledged. The majority of these birds (9 of 13) were from Mewstone, 3 were from Pedra Branca and 1 was from Albatross Island. Ten $(21 \%)$ individuals clearly fledged but transmission ceased within $5 \mathrm{~d}$ of fledging with no movements further than $100 \mathrm{~km}$ from the island (Table 2). The remaining 25 (52\%) individuals fledged and were tracked for between 10 and $80 \mathrm{~d}$ at sea (Fig. 2). The

Table 2. Thalassarche cauta. Summary of days at sea obtained from post-fledging shy albatrosses tagged at 3 colonies

\begin{tabular}{|lcccr|}
\hline Colony & Total deployed & $0 \mathrm{~d}$ & $<5 \mathrm{~d}$ & $>10 \mathrm{~d}$ \\
\hline Albatross Island & 12 & 1 & 1 & 10 \\
Pedra Branca & 12 & 3 & 3 & 6 \\
Mewstone & 24 & 9 & 6 & 9 \\
Total & 48 & 13 & 10 & 25 \\
\hline
\end{tabular}

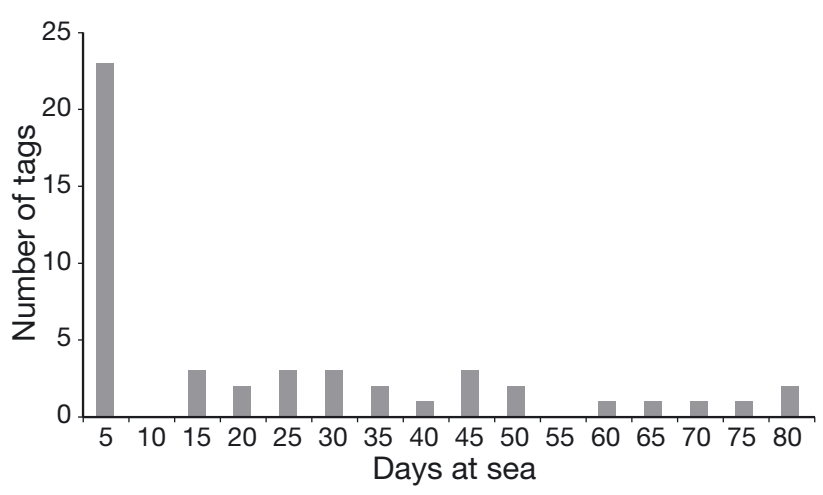

Fig. 2. Thalassarche cauta. Frequency distribution of the number of days tracked at sea obtained from the 48 satellite transmitters deployed on post-fledging shy albatrosses between 1996 and 2006
$80 \mathrm{~d}$ maximum was obtained from units deployed in 1996, which had the largest battery of any units deployed in the present study. At the colony scale, Albatross Island birds were tracked at sea for longer (mean $\pm 1 \mathrm{SD}, 44 \pm 22$ d) than either Pedra Branca or Mewstone $\left(21 \pm 21\right.$ and $20 \pm 24 \mathrm{~d}$, respectively, ANOVA $F_{2,32}$ $=4.15, \mathrm{p}=0.025)$. Assuming that neither attachment nor transmitter failure was a factor, survival of fledging juveniles differed between colonies and was highest for Albatross Island (83\%), intermediate for Pedra Branca (50\%) and lowest for Mewstone (38\%).

There was no relationship between the mass of satellite transmitter and whether individuals ultimately did not fledge, ceased within $5 \mathrm{~d}$ or less of fledging or transmitted beyond $10 \mathrm{~d}$ at sea $\left(\chi^{2}{ }_{4}=4.12, \mathrm{p}>0.1\right)$. Fledging dates inferred from the Argos data ranged from April 11 to May 7 in each of the 4 tracking seasons. There was a significant positive relationship between mass of the bird at deployment and fledging date (i.e. heavier birds fledged later; $r=0.459, t_{30}=$ $2.853, \mathrm{p}<0.001)$. There were equal numbers of males and females (19 and 19) among the 38 individuals for which gender was determined. Males were significantly heavier than females (average 5.6 and $5.1 \mathrm{~kg}$, respectively; $t_{36}=-2.75, \mathrm{p}<0.05$ ), although there was no difference between genders in the time between deployment and fledging $\left(t_{27}=0.768, \mathrm{p}>0.1\right)$. There was no relationship with either mass $\left(\mathrm{r}=-0.025, t_{30}=\right.$ $-0.138, \mathrm{p}>0.5)$ or gender $\left(t_{27}=-0.194, \mathrm{p}>0.5\right)$ with respect to the number of days of at-sea data obtained.

\section{Flight characteristics}

Mean daily flight speeds since fledging for the 10 birds that ceased transmitting early was significantly less $\left(4.6 \mathrm{~km} \mathrm{~h}^{-1}\right)$ than the same period for birds that transmitted beyond $10 \mathrm{~d}\left(17.6 \mathrm{~km} \mathrm{~h}^{-1}, t_{488}=-4.39, \mathrm{p}<\right.$ 0.001). The average direction of travel from the colony for the 10 individuals that ceased transmitting was $93^{\circ}$ (eastward direction) compared to $300^{\circ}$ (northwest) for the other 25 birds during the equivalent time period. The difference between the 2 groups was significant $\left(F_{1,33}=5.54, \mathrm{p}<0.05\right)$ and supports the hypothesis of mortality.

Average daily flight speeds across all surviving individuals $(\mathrm{n}=25)$ averaged $18 \mathrm{~km} \mathrm{~h}^{-1}$ and remained constant over the first $30 \mathrm{~d}$ at sea $\left(\mathrm{r}=-0.03, t_{28}=-0.17, \mathrm{p}=\right.$ 0.86). The area occupied each day (measured by the mean number of $50 \mathrm{~km}$ squares individuals were recorded in) showed a decrease with days since fledging $\left(\mathrm{r}=-0.39, t_{28}=-2.26, \mathrm{p}=0.03\right)$. These data are consistent with juvenile shy albatross developing a more focused foraging strategy with increasing time since fledging. 


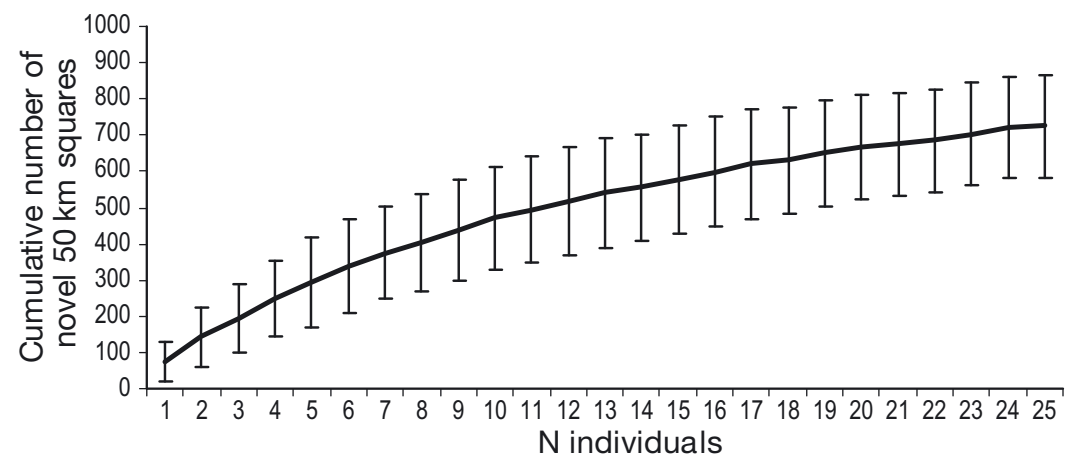

Fig. 3. Thalassarche cauta. Saturation curve analysis of the post-fledging shy albatrosses satellite-tracking sample size. To assess how effectively the tracking sample size of individuals might describe the population-level at-sea distribution, we used time-spent-in-squares in a saturation curve analysis. The cumulative number of average squares occupied was plotted against the number of individuals tracked at sea. The extent to which the slope of the plotted line approaches an asymptote provides an estimate of how effectively the sample size captures the spatial diversity of the species (see 'Materials and methodsData analysis')

\section{At-sea distribution}

Analysis of foraging behaviour and distribution of juvenile shy albatrosses was restricted to those 25 individuals that survived. The saturation curve analysis of the tracking data shows evidence towards saturation (i.e. tending towards an asymptote) and suggests that the sample size of 25 individuals in the present study is beginning to capture the core foraging areas of juvenile shy albatrosses, at least during the first 3 mo after fledging (Fig. 3). Extrapolation of a logarithmic trend line fitted to the saturation curve suggests that a sample size of over 65 individuals would be required for essentially complete saturation at the spatial scale and time period covered in the present study.

After fledging, juvenile birds from all 3 colonies tended to disperse in a northwest direction to continental shelf waters off southern Australia, particularly between $135^{\circ} \mathrm{E}$ and $145^{\circ} \mathrm{E}$ (Fig. 4). This region was an important area for all colonies, especially Albatross Island and Pedra Branca. All 10 Albatross Island birds remained exclusively within the Australian Economic Exclusion Zone (EEZ). Tracked birds from Pedra Branca spent $97 \%$ of the time in Australian waters and the remaining $3 \%$ in international waters (3 of 6 individuals). Juveniles from Mewstone spent $77 \%$ of time in the Australian waters, $19 \%$ of time in international waters (8 of 9 individuals) and $5 \%$ of total time obtained within the South African EEZ (1 of 9 individuals).

\section{Patterns in spatial use}

The use of $50 \mathrm{~km}$ squares (all seasons combined) differed between the 3 colonies of shy albatross (Fig. 5). The 10 Albatross Island birds collectively occupied the

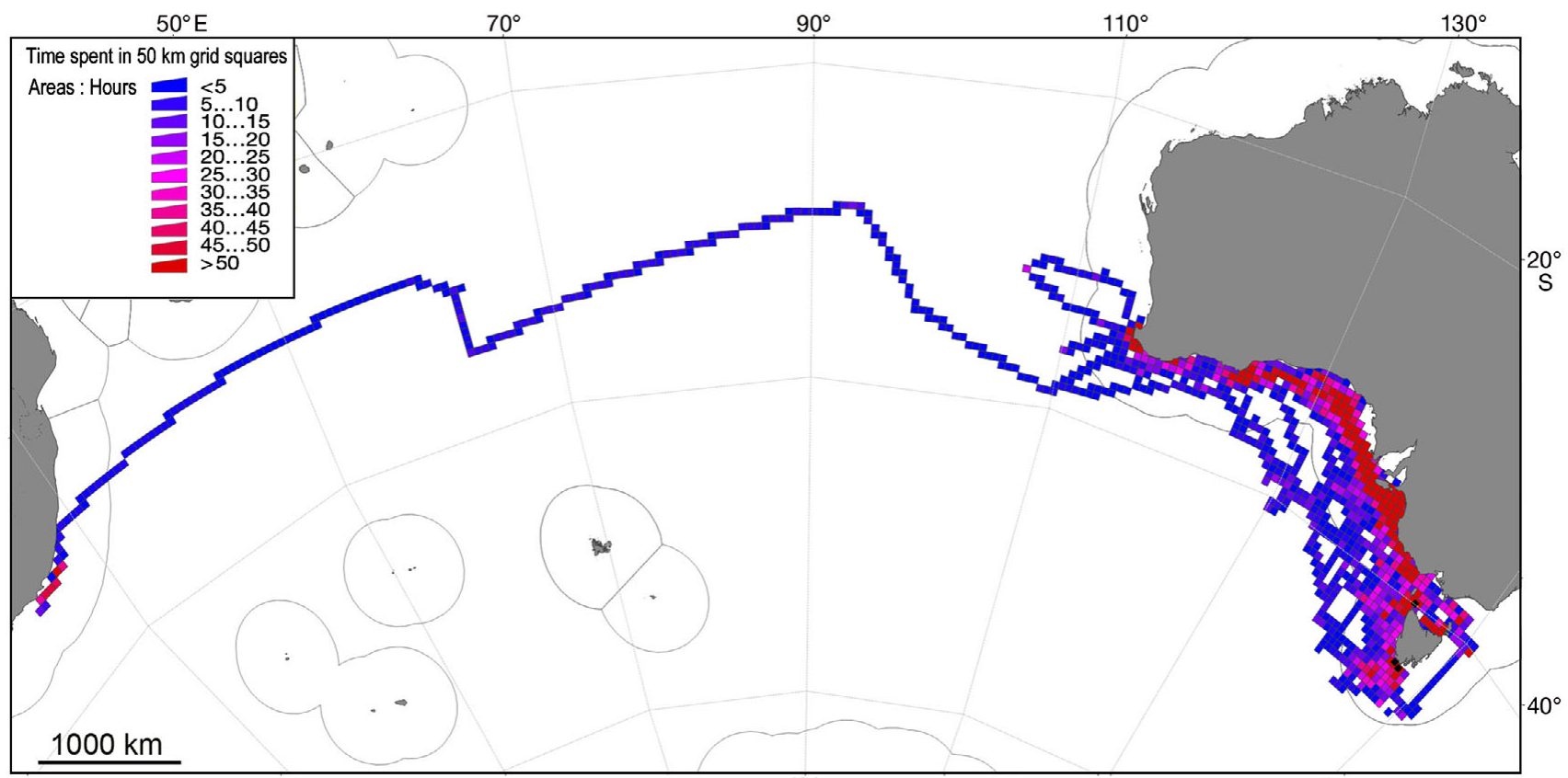

Fig. 4. Thalassarche cauta. At-sea distribution and time spent (within $50 \mathrm{~km}$ squares) of the 25 shy albatrosses tracked 10 or more days after fledging. Solid line indicates the $200 \mathrm{~km}$ Economic Exclusion Zone 

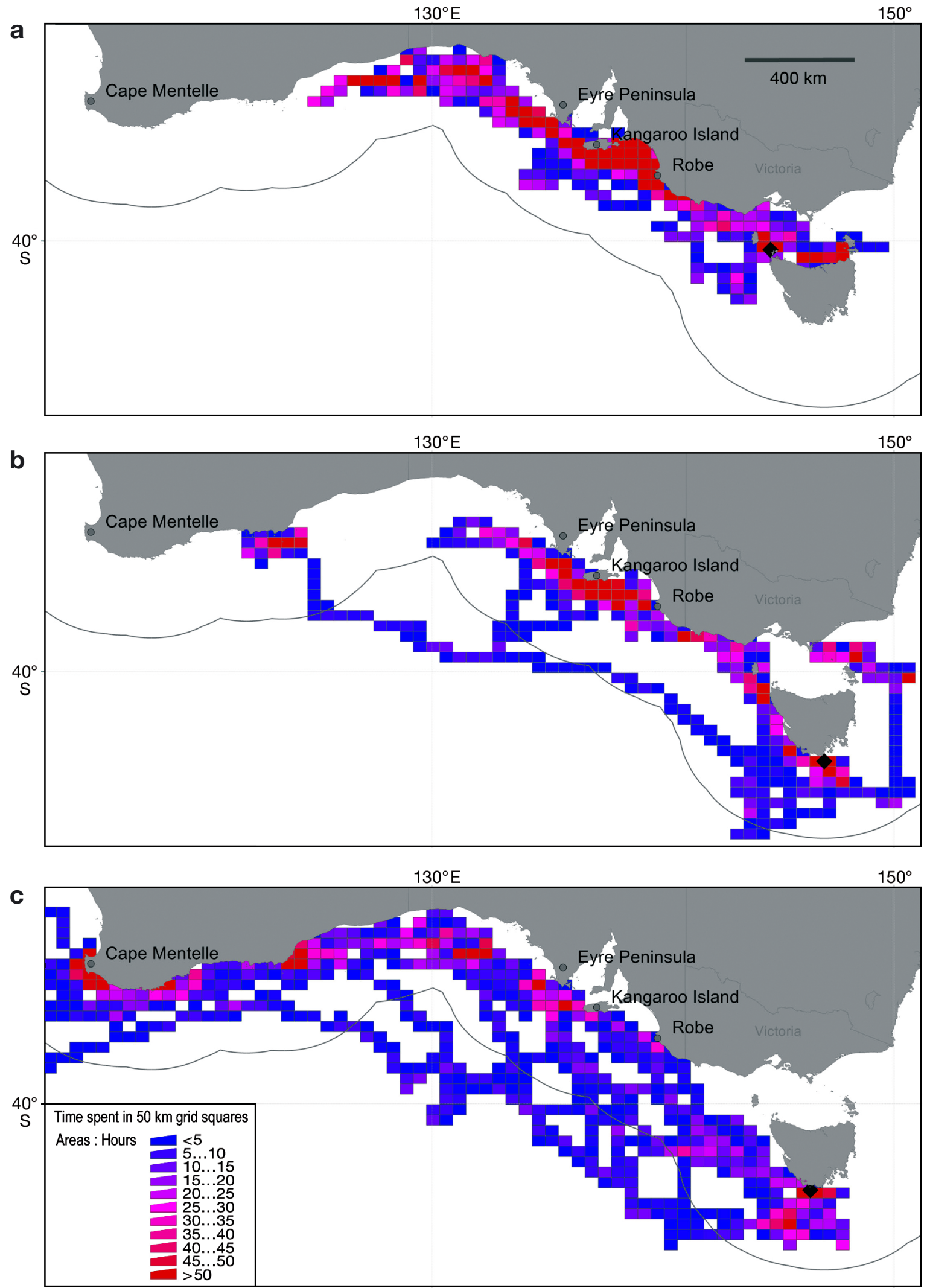

Fig. 5. Thalassarche cauta. Range and focal foraging areas for post-fledging shy albatrosses from each colony: (a) Albatross Island, (b) Pedra Branca and (c) Mewstone 
smallest area (recorded in $31 \%$ of the total 697 grid squares of $50 \mathrm{~km}$ occupied in the present study) and exhibited the highest level of concentration, primarily focused in the area between Robe and Kangaroo Island (Fig. 5a). Birds from Mewstone $(\mathrm{n}=9)$ occupied the widest spatial range (recorded in $72 \%$ of the total grid squares) and displayed minimal concentration of foraging at the colony scale (Fig. 5c). There was little spatial overlap between Mewstone and Albatross Island birds, with only $16 \%$ of all squares occupied by these 2 colonies in common. Fledglings tracked from Pedra Branca $(\mathrm{n}=6$ ) had a range similar to Albatross Island (34\% of total grid squares) and concentration of foraging that was intermediate to Albatross Island and Mewstone (Fig. 5b). This population showed greater overlap of foraging areas with Albatross Island birds than with Mewstone birds (22\% of $50 \mathrm{~km}$ squares in common compared to $16 \%$ ).

Patterns in the utilisation of novel $50 \mathrm{~km}$ squares also differed between the 3 populations. Albatross Island individuals spent significantly more days in previously occupied waters (average of $54 \%$ of days, $n=10$ ) than did Pedra Branca or Mewstone (28\%, n = 6 and $16 \%$, $\mathrm{n}=9$ respectively) (ANOVA $F_{2,22}=22.4, \mathrm{p}<0.001$, Tukey HSD: Albatross Island-Mewstone: $\mathrm{p}<0.001$, Albatross Island-Pedra Branca: $\mathrm{p}<0.01$, Pedra BrancaMewstone: $\mathrm{p}>0.1$ ). Thus, compared to the 2 southern populations, juveniles from the Albatross Island population occupied fewer $50 \mathrm{~km}$ squares in total, and at the scale of the individual, birds from this population showed greater tendency to re-use squares.

\section{Changes in foraging behaviour with time since fledging}

The values of SST over time since fledging predicted by the mixed-effect model shows that Albatross Island birds initially fledged into waters of higher temperature than the 2 southern populations (Fig. 6). This is expected because of the more northern location of this colony. Shy albatross from all colonies tended to occupy waters of higher SST with time since fledging, and birds from all 3 colonies foraged in waters of similar temperature by the end of the $30 \mathrm{~d}$ period.

The mixed-effects models showed a more complex interaction between association with chl $a$, time since fledging and colony (Fig. 7). There were no clear temporal trends; however, Albatross Island birds initially fledged into waters of higher productivity than the 2 southern populations and remained so throughout the $30 \mathrm{~d}$. However, predictions showed more uncertainty than SST relative to between-colony differences, with Fig. 7 indicating that the only statistically significant differences were observed between the Albatross Island and Mewstone colonies.

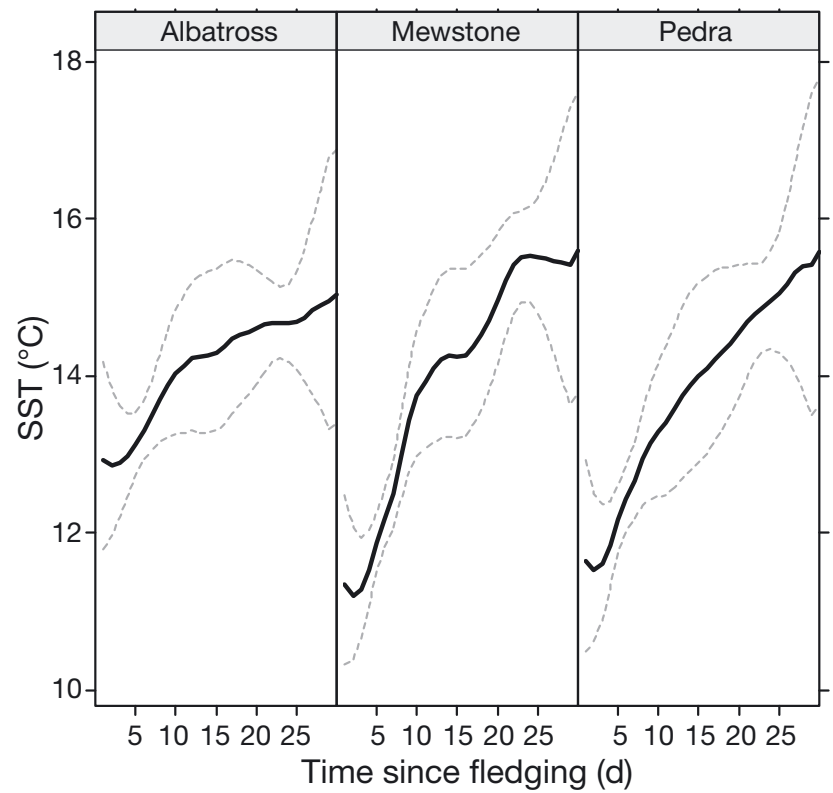

Fig. 6. Predicted response curves for sea surface temperature (SST) from fitted linear mixed-effects models for Albatross Island (left panel), Pedra Branca (middle panel) and Mewstone (right panel). Dashed lines represent SE

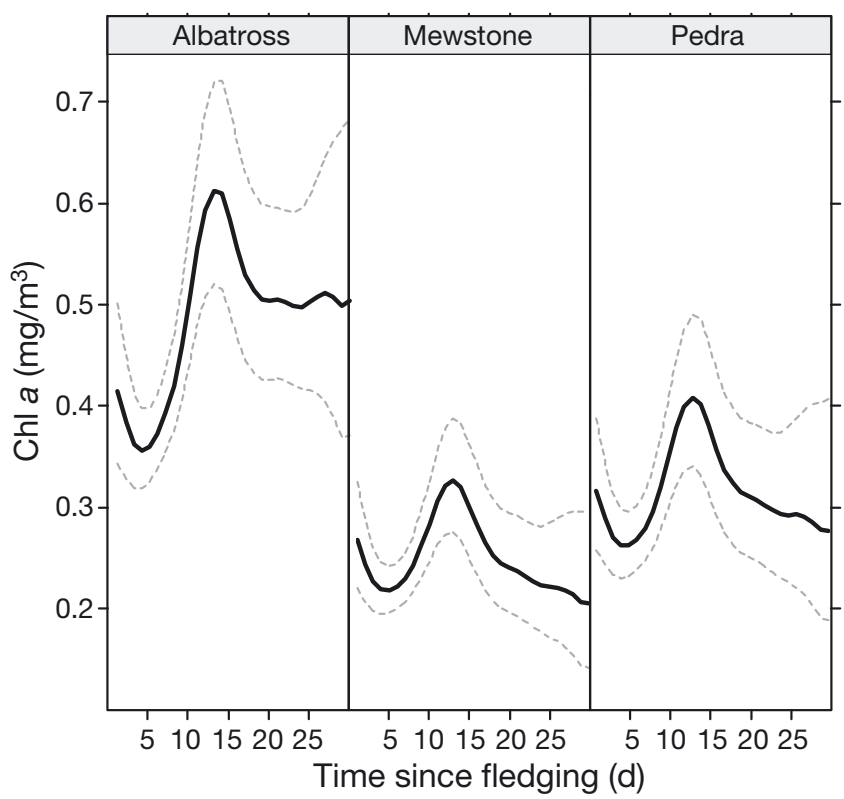

Fig. 7. Predicted response curves for chl a from fitted linear mixed-effects models for Albatross Island (left panel), Pedra Branca (middle panel) and Mewstone (right panel). Dashed lines represent SE

The LMM predictions for bathymetry showed that Albatross Island birds occupied significantly shallower waters than either 2 of the southern populations upon fledging and continued to do so throughout the subsequent $30 \mathrm{~d}$ period (Fig. 8). Initially fledging into deep waters, Pedra Branca and Mewstone birds tended to 


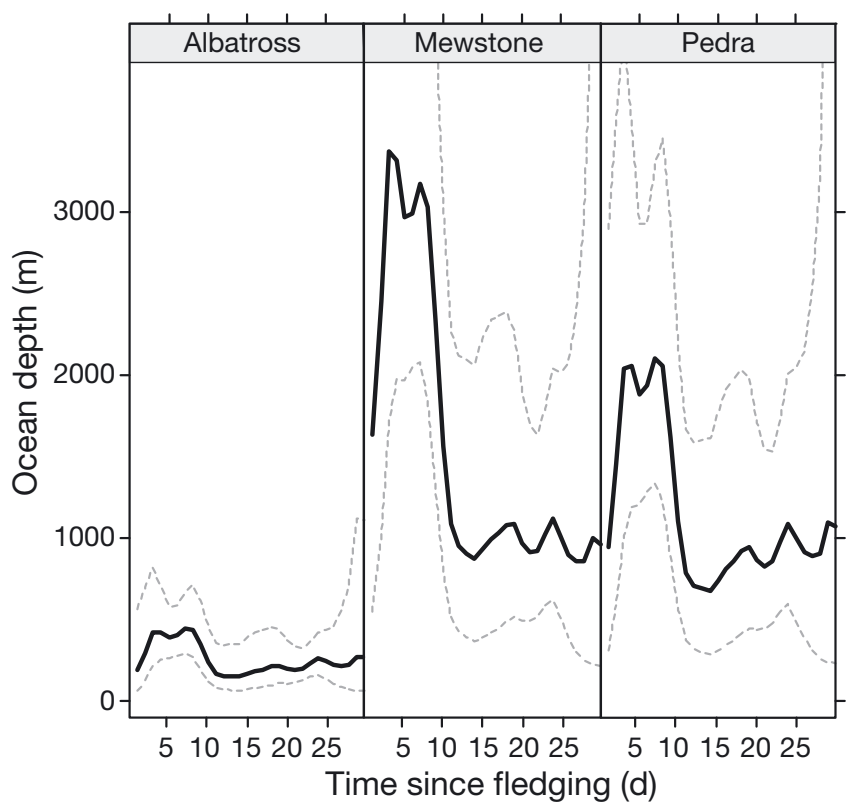

Fig. 8. Predicted response curves for bathymetry from fitted linear mixed-effects models for Albatross Island (left panel), Pedra Branca (middle panel) and Mewstone (right panel). Dashed lines represent SE

occupy progressively shallower waters over time since fledging. Uncertainty in the predictions indicates substantially more individual variation in the depth of waters occupied by individuals from these 2 colonies compared to Albatross Island birds.

\section{DISCUSSION}

This satellite tracking study of juvenile shy albatrosses is the first to report on the distribution and postfledging life-history stage of an albatross species that encompasses all breeding colonies and a range of years. The results demonstrate clear differences between the 3 populations in terms of post-fledging survival as well as at-sea distribution, which in turn has implications for the risk of fisheries bycatch. Regional and environmental factors may have a role in driving these differences.

\section{Fledging and flight characteristics}

In other seabird species a relationship has been demonstrated between the body condition of a chick and subsequent survival (e.g. Dann 1988, Weimerskirch et al. 2000a). Noting that mass alone may be a biased indicator of body condition if not scaled for body size (e.g. Chastel et al. 1995), in the present study there was no relationship between mass at deployment and survival of post-fledging shy albatrosses. Provisioning studies on Albatross Island show that shy albatross chicks attain a peak mass of $5.5 \mathrm{~kg}$ around $109 \mathrm{~d}$, and fledged at masses of $5 \mathrm{~kg}$ at around $127 \mathrm{~d}$ (Hedd et al. 2002). The average mass of chicks at the time of transmitter attachment in the present study was $5.6 \mathrm{~kg}$ and an average of $17 \mathrm{~d}$ until fledging occurred. However, chicks are still occasionally provisioned in the late stages of chick rearing (Hedd et al. 2002), meaning chicks in the present study fledged at an unknown mass and as such, the lack of relationship between mass and survival may be artificial.

More birds failed to fledge (i.e. provided no days at sea) on Mewstone and Pedra Branca than on Albatross Island. This may be related to differences in the topography of the 3 islands. Both southern islands are rocky, host little vegetation or soil deposits, and are characterised by steep slopes and cliff areas. Albatross Island is well vegetated with comparatively gentle slopes. Chicks on this island are quite mobile prior to fledging, having space and opportunity for wing exercise and flying practice, and a choice of departure locations and direction. In contrast, pre-fledging chicks on the southern rocky islands appear more confined to the area of the nest and presumably are more likely to take flight in sub-optimal conditions.

If chicks do successfully leave the island, the satellite tracking data show that the initial days at sea are a critical period for determining survival. Juveniles that apparently died soon after fledging exhibited slow speeds and a down-wind trajectory, not travelling further than $100 \mathrm{~km}$ from the island before transmission ceased. These observations are all consistent with passive drifting behaviours.

Patterns of mortality in the tracking data is supported by band recoveries. Between 1960 and 2006, over 30000 pre-fledging shy albatross chicks have been banded, the majority $(\sim 80 \%)$ of these on Albatross Island (DPIPWE unpubl.). Recovery and reporting of bands away from the natal island is a rare event, and only 183 bands have been recovered as juveniles (i.e. within $4 \mathrm{yr}$ of banding). Such recoveries are almost exclusively dead beach-washed individuals and the time lapsed between banding and recovery typically overestimates the age at death. In spite of this, over $50 \%$ of all juvenile recoveries were within the first 4 mo of fledging, and $67 \%$ (122 of 183) were recovered within the first year. Furthermore, $41 \%$ of bands recovered within a year of fledging were found less than $100 \mathrm{~km}$ from the natal colony. The large proportion of recently fledged individuals amongst the band return data, together with the proximity of these recoveries to the natal colony, is consistent with the satellite tracking results and the conclusion that juvenile mortality is at its greatest for naive birds soon after fledging. 
In contrast to those that died, individuals in the present study that appeared to survive flew at greater speeds and in a northwest direction. At the latitudes of the natal colonies $\left(40^{\circ}\right.$ to $\left.42^{\circ} \mathrm{S}\right)$ this direction is predominantly across prevailing westerly winds, conferring energetic advantages for gliding albatross (Weimerskirch et al. 2000b). These behaviours are consistent with active and directed travel.

Individual patterns in post-fledging foraging behaviour provide some insight into the question of whether young albatrosses fledge with innate foraging and the navigation skills of adult birds or whether they learn them over time. The flight speeds of juvenile shy albatross showed little change over time and were similar to those recorded from adult birds (Hedd et al. 2001). The area covered each day-as measured by the number of $50 \mathrm{~km}$ squares-also remained constant with time since fledging. These foraging characteristics, i.e. flight speed and area covered, are consistent with a slow, continuous search for food (with individuals learning as they mature) rather than rapid commuting to a particular area following innate cues.

It is reasonable to expect that whether individual chicks survive the first few days of fledging will be influenced by individual quality and physical condition at time of fledging. However, the clear colony differences evident in mortality rates suggest some regional and/or environmental factors may also be significant (see 'Discussion - Habitat use').

\section{Juvenile dispersal and colony differences}

The general pattern for post-fledging shy albatrosses was to travel northwest from their natal island to the shelf waters of southern Australia. Fledglings from Albatross Island had the least distance to travel and tended to concentrate in more eastern waters, always remaining within continental shelf regions. Mewstone and Pedra Branca birds travelled further and dispersed more widely across oceanic regions than Albatross Island birds, but ultimately also reached southern Australian shelf areas. The notable exception was a female from Mewstone in 2004 that, upon reaching the shelf in south Western Australia, continued west across the Indian Ocean to forage in waters off South Africa.

The band recovery data discussed in the previous section also reflects the spatial distribution and the population differences identified in the satellite tracking data. The majority of band returns are from Albatross Island $(n=166)$, some from Mewstone $(n=17)$ and none from Pedra Branca, the latter reflecting the small population size and banding effort. Band returns are concentrated in the shelf waters off southern and eastern Australia (>90\% of recoveries) and confirm this region to be the primary foraging location for this species. As might be expected (given the increased sample size in terms of individuals and time), band recoveries reveal a wider distribution for Albatross Island juveniles than the tracking data, with isolated recoveries extending the full range further north and west.

Although the sample is small for Mewstone, 7 of 17 bands were recovered in South African waters, 2 of which were within the first 6 mo of fledging. Given the unlikely event that a band is recovered, the fact that $40 \%$ of bands and 1 of the 5 individuals from this population tracked longer than 3 wk reached South Africa suggests this may be a commonly utilised foraging ground for the Mewstone population.

\section{Habitat use}

The waters into which Albatross Island individuals fledged were shallower and warmer than those initially occupied by birds from Mewstone and Pedra Branca. The predominantly northwest trajectory meant that, over time, fledglings from the 2 southern populations attained the latitudes of Albatross Island birds and occupied waters of similar depth and temperature, although these 2 populations exhibited more individual variation.

In contrast to SST and bathymetry, there were clear and persistent population differences in the productivity of the waters occupied by post-fledging shy albatrosses, with Albatross Island birds consistently in waters of higher chl a concentration than the 2 southern populations. The waters off southern Australia are not considered highly productive (Ridgway \& Condie 2004, Poloczanska et al. 2007). However, the focal foraging areas of juvenile shy albatross, and particularly Albatross Island individuals, matches closely with areas of locally enhanced productivity and known feeding aggregations of other species, including blue whales Balaenoptera musculus (Gill 2002), and bluefin tuna Thunnus thynnus (Willis \& Hobday 2007). In particular, the upwelling associated with Kangaroo Island, the Eyre Peninsula and Cape Mentelle, as well as meso-scale eddies along the shelf break (Ward et al. 2006) were utilised extensively by birds in the present study. The population differences in chl a concentration of occupied waters likely reflect the physical location of the 3 breeding islands. Albatross Island is adjacent to these productive features and juveniles from this population fledge immediately into waters of higher chl a concentration than Mewstone and Pedra Branca individuals. Individuals from the 2 southern populations also have to travel greater distances to reach these areas. With a continual, undirected search strategy (as opposed to directed travel), this results in 
greater areas covered and a larger time delay necessary to reach the more productive shelf waters that are in close proximity to Albatross Island.

Population differences were also apparent in the way that individuals utilised the foraging areas over time (i.e. the novel cell analysis). Albatross Island individuals had the greatest tendency to remain within or return to previously occupied waters. This would be consistent with encountering a favourable foraging area (although other explanations, such as local wind effects, are possible). In contrast, juvenile birds from Mewstone and Pedra Branca showed greater tendency to be continually moving into new areas-potentially evidence of naive, hungry birds, failing to locate patchily distributed food resources. This trend, in combination with the fact that Albatross Island birds fledged into waters of greater chl a concentration than the 2 southern populations, may provide insight into the higher apparent survival of post-fledging birds from this colony.

Increased chl a concentration alone cannot account for the higher chances of post-fledging survival in Albatross Island birds indicated in the present study. Associations between foraging areas and primary productivity are likely to be indirect given the trophic separation (Grémillet et al. 2008). Seabirds are abundant in the waters of Bass Strait and southern Australia during the non-breeding, winter months (Reid et al. 2002). This includes adult shy albatross from all 3 populations in large numbers as well as other albatross species. Several studies have suggested that local enhancement (locating prey through observing conspecifics) is an important method of prey detection (e.g. Davoren et al. 2003, Grünbaum \& Veit 2003) and so too by observing other seabird, marine mammal or fish species (e.g. Silverman et al. 2004).

Naive shy albatross fledglings from Albatross Island may therefore have an advantage over the 2 southern populations during the critical first few days at sea by virtue of (1) fledging immediately into more productive waters and (2) more opportunity to learn how to locate prey within these waters from other marine species.

\section{Comparison with adult distribution}

Satellite tracking and geolocation of adult shy albatross during the winter period show adults from all 3 populations foraging almost exclusively in Tasmanian and Bass Strait waters (DPIPWE unpubl.). Non-breeding adult birds from Mewstone and Pedra Branca populations forage at significantly greater distances from their colony than do Albatross Island individuals during this period (DPIPWE unpubl.). Satellite-tracked adult shy albatross repeatedly re- turned to the island during the winter non-breeding period, a common behaviour confirmed by radio tracking (attendance) studies (Hedd \& Gales 2005) and observational data.

Despite the broad spatial overlap, there was little overlap between the core foraging areas of juveniles and adults from the same islands. The productive zone west of Albatross Island around the Bonney upwelling (offshore Robe) and Kangaroo Island are heavily exploited by the juveniles from all populations but much less so by adult birds, despite the relative proximity. Limited overlap between the foraging zones of juvenile and adult birds has also been documented in wandering albatrosses from the Crozet (Weimerskirch et al. 2006), where juveniles forage in waters less productive than those utilised by adults. Weimerskirch et al. (2006) suggest competitive exclusion to explain this behaviour in wandering albatross; however, since the Albatross Island population is still significantly below historical pre-exploitation numbers, this may not be the case here. An alternative view is that there are benefits for adults remaining resident in the waters within close proximity to the breeding colony (perhaps in terms of nest site defence and/or pair bond) that are offset by increased foraging efficiency with age.

\section{Conservation implications}

The information on juvenile shy albatross distribution can be used to estimate overlap with key threatening processes, such as with fishing operations. Within the Australian EEZ, there is extensive temporal and spatial overlap between juvenile shy albatross from all 3 populations and a range of domestic trawl fisheries. Bycatch rates on Australian trawl vessels are unknown, but given the interactions between albatrosses and trawl fisheries in waters of other countries, including New Zealand (Conservation Services Programme 2008), South America (Sullivan et al. 2006, GonzálezZevallos et al. 2007) and South Africa (Watkins et al. 2008), the potential threat needs further investigation. If there is significant bycatch in the Australian trawl industry then all 3 populations are likely to be affected. With respect to longline fishing in the Australian EEZ, there is minimal spatial and temporal overlap with juvenile shy albatross foraging regions identified by the satellite tracking data. Given the generally effective mitigation measures and consequently low bycatch rates (Baker et al. 2007), longline-related mortality is likely to have minimal impact on juvenile shy albatrosses in Australian waters.

Both tracking and band return data suggest that chicks fledging from Mewstone commonly occur in international waters south of Australia en route to the continen- 
tal shelf, the high seas of the Indian Ocean and the waters of South Africa. Interactions with international fleets in the high seas are potentially important, with the Commission for the Conservation of Southern Bluefin Tuna (CCSBT) and the Indian Ocean Tuna Commission (IOTC) tuna fisheries of greatest relevance and bycatch remains a concern in both (Baker et al. 2007). In South African waters, bycatch rates of albatrosses are high in both trawl (Watkins et al. 2008) and longline (Petersen et al. 2007) fisheries. Approximately 4000 juvenile birds fledge from Mewstone each year (DPIPWE unpubl.). It seems reasonable, based on banding and tracking data, to assume that at least $10 \%$ (i.e. 400 individuals) may travel to South African waters each year. The high bycatch rates reported in these waters may therefore have a detrimental impact on the Mewstone population. This is of concern as it is the largest shy albatross colony and population trends are unknown.

\section{Survival implications}

Results presented in the present study indicate that nearly half of the 48 satellite transmitters deployed failed to provide at-sea data because chicks died on fledging or soon after. Young birds are naive and must learn both to fly and to forage for themselves. Since chicks fledge at a low mass and often with high parasite loads (Hedd et al. 2002), their survival rates are likely to be low in the first few months. The data presented here suggests that the northern Albatross Island colony may have greater rates of survival in the critical postfledging period than either of the 2 southern populations. The chl a data show that Albatross Island birds are consistently in waters of higher productivity. For naive juveniles with a continual search strategy, chance is likely to play a large role in determining whether an individual initially encounters productive waters. Albatross Island chicks also fledge in the vicinity of more productive waters than either of the 2 southern populations. The greater distances birds from these populations have to cover before encountering favourable areas, in the critical post-fledging period, could result in different rates of juvenile survival.

Acknowledgements. This study was made possible by $\mathrm{T}$. Nevard and D. Bellamy of the Conservation Foundation through their dedication to conservation and inspiration in facilitating the 'Big Bird Race'. Ladbrokes provided the funding for the satellite transmitters in 2004 and 2005. N. Brothers, A. Hedd, D. Pemberton, A. Terauds and A. Irvine assisted with the deployment of satellite transmitters. We thank M. Double for genetic analysis and M. Sumner for assistance with the package 'trip'. M. Double, G. Tuck and S. Nicol provided valuable comments on an early draft of the paper. Four reviewers provided comprehensive and insightful comments that greatly improved the manuscript.

\section{LITERATURE CITED}

Abbott CL, Double MC, Gales R, Baker GB, Lashko A, Robertson CJR, Ryan P (2006) Molecular provenance analysis for shy and white-capped albatrosses killed by fisheries interactions in Australia, New Zealand and South Africa. Conserv Genet 7:531-542

Armstrong WJT (1910) On Albatross Island. Emu 9:155-157

Arnold JM, Brault S, Croxall J (2006) Albatross populations in peril? A population trajectory for black-browed albatrosses at South Georgia. Ecol Appl 16:419-432

- Baker GB, Gales R, Tuck GN, Abbott CL and others (2007) A global assessment of the impact of fisheries-related mortality on shy and white-capped albatrosses: conservation implications. Biol Conserv 137:319-333

> Barbraud C, Weimerskirch H (2005) Environmental conditions and breeding experience affect costs of reproduction in blue petrels. Ecology 86:682-692

Bartle S (1991) Incidental capture of seabirds in the New Zealand subantarctic squid trawl fishery, 1990. Bird Conserv Int 1:351-359

> Bestley S, Patterson TA, Hindell MA, Gunn JS (2008) Feeding ecology of wild migratory tunas revealed by archival tag records of visceral warming. J Anim Ecol 77:1223-1233

Birdlife International (2004) Tracking ocean wanderers; the global distribution of albatrosses and petrels. Results from the Global Procellariiform Tracking Workshop, 1-5 September 2003, Gordon's Bay, South Africa. Birdlife International, Cambridge, UK

Bradshaw CJA, Higgins J, Michael KJ, Wotherspoon S, Hindell MA (2004) At-sea distribution of female southern elephant seals relative to variation in ocean surface properties. ICES J Mar Sci 61:1014-1027

Brothers NP, Reid TA, Gales RP (1997) At-sea distribution of Shy Albatrosses Diomedea cauta cauta derived from records of band recoveries and colour-marked birds. Emu 97:231-239

Burger AE, Shaffer SA (2008) Application of tracking and data-logging technology in research and conservation of seabirds. Auk 125:253-264

Chastel O, Weimerskirch H, Jouventin P (1995) Influence of body condition on reproductive decision and reproductive success in the blue petrel. Auk 112:964-972

Conservation Services Programme (2008) Summary of autopsy reports for seabirds killed and returned from observed New Zealand fisheries: 1 October 1996-30 September 2005, with specific reference to 2002/03, 2003/04, 2004/05. Department of Conservation, Wellington

Cuthbert R, Ryan PG, Cooper J, Hilton G (2003) Demography and population trends of the Atlantic yellow-nosed Albatross. Condor 105:439-452

Dann P (1988) An experimental manipulation of clutch size in the little penguin Eudyptula minor. Emu 88:101-103

> Davoren GK, Montevecchi WA, Anderson JT (2003) Search strategies of a pursuit-diving marine bird and the persistence of prey patches. Ecol Monogr 73:463-481

Diggle PJ, Heagerty P, Liang K, Zeger SL (2001) Analysis of longitudinal data, 2nd edn. Oxford University Press, Oxford

Fernández P, Anderson DJ, Sievert PR, Huyvaert K (2001) Foraging destinations of three low-latitude albatross (Phoebastria) species. J Zool 254:391-404

Gill P (2002) A blue whale (Balaenoptera musculus) feeding ground in a southern Australian coastal upwelling zone. J Cetacean Res Manag 4:179-184

Gilmour RA, Cullis BR, Welham SJ, Thompson R (1999) Asreml reference manual. Biometric Bulletin No. 3, NSW Agriculture, Orange, New South Wales 
González-Zevallos D, Yorio P, Caille G (2007) Seabird mortality at trawler warp cables and a proposed mitigation measure: a case of study in Golfo San Jorge, Patagonia, Argentina. Conserv Biol 136:109-116

- Grémillet D, Lewis S, Drapeau L, van Der Lingen CD and others (2008) Spatial match-mismatch in the Benguela upwelling zone: should we expect chlorophyll and seasurface temperature to predict marine predator distributions? J Appl Ecol 45:610-621

Griffiths R, Tiwari B (1995) Sex of the last wild Spix's macaw. Nature 375:454

> Grünbaum D, Veit R (2003) Black-browed albatrosses foraging on Antarctic krill: density-dependence through local enhancement? Ecology 84:3265-3275

Hays GC, Akesson S, Godley BJ, Luschi P, Santidrian P (2001) The implications of location accuracy for the interpretation of satellite tracking data. Anim Behav 61:1035-1040

Hays GC, Bradshaw CJA, James MC, Lovell P, Sims DW (2007) Why do Argos satellite tags deployed on marine animals stop transmitting? J Exp Mar Biol Ecol 349:52-60

> Hedd A, Gales R (2005) Breeding and overwintering ecology of shy albatrosses in southern Australia: year-round patterns of colony attendance and foraging-trip durations. Condor 107:375-387

> Hedd A, Gales R, Brothers N (2001) Foraging strategies of shy albatross Thalassarche cauta breeding at Albatross Island, Tasmania, Australia. Mar Ecol Prog Ser 224:267-282

$>$ Hedd A, Gales R, Brothers N (2002) Provisioning and growth rates of shy Albatrosses at Albatross Island, Tasmania. Condor 104:12-29

Hindell MA, Bradshaw CJA, Sumner MD, Michael KJ, Burton HR (2003) Dispersal of female southern elephant seals and their prey consumption during the austral summer: relevance to management and oceanographic zones. J Appl Ecol 40:703-715

> Huin N (2002) Foraging distribution of the black-browed Albatross, Thalassarche melanophris, breeding in the Falkland Islands. Aquat Conserv Mar Freshw Ecosyst 12: 89-99

Hyrenbach KD, Fernandez P, Anderson DJ (2002) Oceanographic habitats of two sympatric North Pacific albatrosses during the breeding season. Mar Ecol Prog Ser 233: 283-301

Inchausti P, Weimerskirch H (2001) Risks of decline and extinction of the endangered Amsterdam albatross and the projected impact of long-line fisheries. Biol Conserv 100:377-386

IUCN (2008) IUCN Red List of threatened species. Www. iucnredlist.org

> Jouventin P, Weimerskirch H (1990) Satellite tracking of wandering albatrosses. Nature 343:746-748

> Lawton K, Kirkwood R, Robertson G, Raymond B (2008) Preferred foraging areas of Heard Island albatrosses during chick raising and implications for the management of incidental mortality in fisheries. Aquat Conserv Mar Freshw Ecosyst 18:309-320

> Nel DC, Ryan PG, Nel JL, Klages NTW, Wilson RP, Robertson G, Tuck GN (2002) Foraging interactions between wandering Albatrosses Diomedea exulans breeding on Marion Island and long-line fisheries in the southern Indian Ocean. Ibis 144:E141-E154

- Nevoux M, Weimerskirch H, Barbraud C (2007) Environmental variation and experience-related differences in the demography of the long-lived black-browed albatross. J Anim Ecol 76:159-167

Petersen S, Honig MB, Nel D (2007) The impact of longline fisheries on seabirds in the Benguela Current Large
Marine Ecosystem. In: Petersen S, Nel D, Omardien A (eds) Towards an ecosystem approach to longline fisheries in the Benguela. WWF South Africa Report Series, 2007/ Marine/001

Pinaud D, Weimerskirch H (2002) Ultimate and proximate factors affecting the breeding performance of a marine top-predator. Oikos 99:141-150

Pinaud D, Weimerskirch H (2007) At-sea distribution and scale-dependent foraging behaviour of petrels and albatrosses: a comparative study. J Anim Ecol 76:9-19

Plomley NJB (ed) (1966) Friendly mission-the Tasmanian journals and papers of George Augustus Robinson: 18291834. Tasmanian Historical Research Association, Quintus Publishing, Hobart

Poloczanska ES, Babcock RC, Butler A, Hobday AJ and others (2007) Climate change and Australian marine life. Oceanogr Mar Biol Annu Rev 45:407-478

Prince PA, Wood AG, Barton T, Croxall JP (1992) Satellite tracking of wandering albatrosses (Diomedea exulans) in the south-Atlantic. Antarct Sci 4:31-36

Reid TA, Hindell MA, Eades DW, Newman M (2002) Seabird atlas of south-eastern Australian waters. Birds Australia, Melbourne

Ridgway K, Condie SA (2004) The 5500-km-long boundary flow off western and southern Australia. J Geophys Res Oceans 109:C04017 doi:10.1029/2003JC001921

> Silverman ED, Veit RR, Nevitt GA (2004) Nearest neighbors as foraging cues: information transfer in a patchy environment. Mar Ecol Prog Ser 277:25-36

- Sullivan BJ, Brickle P, Reid TA, Bone DG, Middleton DAJ (2006) Mitigation of seabird mortality on factory trawlers: trials of three devices to reduce warp cable strikes. Polar Biol 29:745-753

Suryan RM, Sato F, Balogh GR, Hyrenbach KD, Sievert PR, Ozaki K (2006) Foraging destinations and marine habitat use of short-tailed albatrosses: A multi-scale approach using first-passage time analysis. Deep-Sea Res II 53: 370-386

> Tasker ML, Camphuysen CJ, Cooper J, Garthe S, Montevecchi WA, Blaber SJM (2000) The impacts of fishing on marine birds. ICES J Mar Sci 57:531-547

Terauds A, Gales R, Baker GB, Alderman R (2006a) Foraging areas of black-browed and grey-headed albatrosses breeding on Macquarie Island in relation to marine protected areas. Aquat Conserv Mar Freshw Ecosyst 16: 133-146

> Terauds A, Gales R, Baker GB, Alderman R (2006b) Population and survival trends of wandering Albatrosses (Diomedea exulans) breeding on Macquarie Island. Emu 106: 211-218

Trebilco R, Gales R, Baker GB, Terauds A, Sumner MD (2008) At sea movement of Macquarie Island giant petrels: relationships with marine protected areas and regional fisheries management organisations. Biol Conserv 141: 2942-2958

- Tuck GN, Polacheck T, Croxall JP, Weimerskirch H (2001) Modelling the impact of fishery by-catches on albatross populations. J Appl Ecol 38:1182-1196

Veit RR (1999) Behavioural responses by foraging petrels to swarms of Antarctic Krill Euphausia superba. Ardea 87: $41-50$

Verbyla AP, Cullis BR, Kenward MG, Welham SJ (1999) The analysis of designed experiment and longitudinal data using smoothing splines (with discussion). Appl Stat 48: 269-311

> Ward TM, McCleay LJ, Dimmlich WF, Rogers PJ and others (2006) Pelagic ecology of a northern boundary current sys- 
tem: effects of upwelling on the production and distribution of sardine (Sardinops sagax), anchovy (Engraulis australis) and southern bluefin tuna (Thunnus maccoyii) in the Great Australian Bight. Fish Oceanogr 15:191-207

Watkins BP, Petersen SL, Ryan PG (2008) Interactions between seabirds and deep-water hake trawl gear: an assessment of impacts in South African waters. Anim Conserv 11:247-254

Waugh SM, Sagar PM, Cossee RO (1999) New Zealand blackbrowed albatross Diomedea melanophrys impavida and grey-headed albatross D. chrysostoma banded at Campbell Island: recoveries from the South Pacific region. Emu 99:29-35

Weimerskirch H (1992) Reproductive effort in long-lived birds: age-specific patterns of condition, reproduction and survival in the wandering albatross. Oikos 64:464-473

Weimerskirch $H$, Salamolard M, Sarrazin F, Jouventin P (1993) Foraging strategy of wandering albatrosses through the breeding season - a study using satellite telemetry. Auk 110:325-342

Editorial responsibility: Yves Cherel, Villiers-en-Bois, France
Weimerskirch H, Cherel Y, Cuenot-Chaillet F, Ridoux V (1997) Alternative foraging strategies and resource allocation by male and female wandering albatrosses. Ecology 78:2051-2063

Weimerskirch H, Barbraud C, Lys P (2000a) Sex differences in parental investment and chick growth in wandering albatrosses: fitness consequences. Ecology 81:309-318

Weimerskirch H, Guionnet T, Martin J, Shaffer SA, Costa DP (2000b) Fast and fuel efficient? Optimal use of wind by flying albatrosses. Proc R Soc Lond B Biol Sci 267:1869-1874

Weimerskirch H, Akesson S, Pinaud D (2006) Postnatal dispersal of wandering albatrosses Diomedea exulans: implications for conservation of the species. J Avian Biol 37: $23-28$

Welham SJ, Thompson R (1997) Likelihood ratio tests for fixed model terms using residual maximum likelihood. J R Stat Soc B 59:701-714

Willis J, Hobday AJ (2007) Influence of upwelling on movement of southern bluefin tuna (Thunnus maccoyii) in the Great Australian Bight. Mar Freshw Res 58:699-708

Submitted: June 21, 2009; Accepted: March 15, 2010 Proofs received from author(s): April 23, 2010 